\title{
Dementia of frontal lobe type: neuropathology and immunohistochemistry
}

\author{
D M A Mann, P W South, J S Snowden, D Neary
}

\begin{abstract}
Brains from 12 patients dying with a clinical diagnosis of frontal lobe dementia have been examined at post mortem. In pathological terms four groups were encountered. Groups $A$ and $B$ showed severe frontal and temporal lobe atrophy characterised histologically in group $\mathbf{A}$ by severe neuronal loss, spongiform change of the superficial laminae, and mild astrocytosis; in group $B$ severe neuronal loss was accompanied by intense gliosis but with little or no spongiform change. Two patients in this latter group also showed inclusions in frontal cortex and hippocampus typical of "Pick bodies"; such patients were considered as having classic "Pick's disease". Group C patients showed severe striatal atrophy with variable cortical (frontal or temporal) involvement, with histological changes similar to patients in groups $A$ and $B$. The single patient in group $D$ showed mild frontotemporal atrophy with spongiform degeneration of the superficial laminae of the cortex and nigral damage, and was considered to have motor neuron disease with dementia. This study is consistent with previous reports showing that the clinical syndrome of frontal lobe dementia is pathologically heterogeneous. However, the nosological relationships within these pathological variants, and between them and conditions such as progressive aphasia where similar histopathological changes are present, remain uncertain.
\end{abstract}

$(F$ Neurol Neurosurg Psychiatry 1993;56:605-614)

In the not too distant past it was widely accepted that patients with cerebral atrophy could be confidently assumed to have Alzheimer's disease (AD) once cerebrovascular disease, trauma, and alcohol had been excluded, particularly during the presenium. However, it is now becoming increasingly recognised that certain non-Alzheimer forms of cerebral atrophy are more common than has been generally supposed and these may make a significant proportional contribution to all cases of dementia. In several surveys ${ }^{1-3}$ their prevalence, compared with $\mathrm{AD}$, has been estimated as $1: 5,1: 8$, or $1: 11$ respectively. One such condition, clinically termed frontal lobe dementia ${ }^{45}$ or dementia of frontal lobe type (DFT) 1 presents typically with behavioural disturbances that lead to mutism and dementia. In about half of patients affected by DFT, a family history of a similar disorder seems to be present ${ }^{6}$; the pattern of inheritance being suggestive of the action of an autosomally dominant gene. Neuropathological descriptions of the brains of patients dying with DFT, however, remain scant. ${ }^{2-4}$ The nosological and pathological relationships between DFT and Pick's disease and between DFT and other neurodegenerative disorders such as motor neuron disease (MND) with dementia ${ }^{78}$ and progressive aphasia $^{9}$ remain uncertain. We present the neuropathological findings in the brains of 12 consecutive patients dying with a clinical history compatible with that of DFT. ${ }^{16}$

\section{Materials and methods}

Brains were obtained at necropsy from 12 patients with a clinical diagnosis of DFT (see Neary et $a l^{1}$ for criteria and tables 1 and 2 for relevant demographic and clinical details). Brains were fixed, by immersion in $10 \%$ neutral formalin, for three to four weeks, then cut coronally into $2 \mathrm{~cm}$ slices. In some patients the right hemisphere was frozen for neurochemical analysis and in these only the left hemisphere, cerebellum, and brainstem were fixed for histology. From the fixed tissue, blocks were cut from all major cortical and non-cortical regions, processed routinely into paraffin wax, and serially sectioned at $5 \mu \mathrm{m}$ thickness. Certain sections were stained using conventional neurohistological methods including Palmgren silver stain for neurofibrillary tangles ${ }^{10}$ and methenamine silver stain for amyloid ( $\beta / \mathrm{A} 4)$ protein. ${ }^{112}$ Other sections were stained immunohistochemically using a conventional avidin-biotin-peroxidase method $^{12}$ and employing primary antibodies

\begin{tabular}{lllll} 
Table 1 & \multicolumn{5}{l}{ Demographic details of patients 1-12 } \\
\hline Patient & Sex & $\begin{array}{l}\text { Age at } \\
\text { onset (years) }\end{array}$ & $\begin{array}{l}\text { Duration of } \\
\text { illness (years) }\end{array}$ & $\begin{array}{l}\text { Family } \\
\text { history }\end{array}$ \\
\hline 1 & M & c.50 & 11 & + \\
2 & F & 64 & 7 & + \\
3 & F & 53 & 8 & + \\
4 & F & 62 & 1 & n/a \\
5 & M & 61 & 8 & - \\
6 & F & 46 & 10 & + \\
7 & M & 53 & 7 & - \\
8 & M & 50 & 13 & - \\
9 & M & 46 & 23 & - \\
10 & M & 45 & 4 & + \\
11 & M & 59 & 4 & - \\
12 &
\end{tabular}

$\mathrm{n} / \mathrm{a}=$ no details avaiable. 
Table 2 Clinical details of patients 1-12

\begin{tabular}{|c|c|c|c|c|c|c|}
\hline \multirow{2}{*}{$\begin{array}{l}\text { Patient } \\
\text { No }\end{array}$} & \multirow{2}{*}{$\begin{array}{l}\text { Extrapyramidal } \\
\text { features }\end{array}$} & \multicolumn{3}{|c|}{ Prominent behavioural syndrome } & \multirow[b]{2}{*}{$C T$} & \multirow{2}{*}{$\begin{array}{l}\text { SPET } \\
\text { area of } \\
\text { reduced uptake }\end{array}$} \\
\hline & & Apathy & Disinhibition & Stereotypy & & \\
\hline 1 & + & - & + & - & $\mathrm{n} / \mathrm{a}$ & $\mathbf{n} / \mathbf{a}$ \\
\hline 2 & + & - & + & - & $\mathbf{n} / \mathbf{a}$ & $\mathrm{n} / \mathbf{a}$ \\
\hline 3 & ? & - & + & - & $\mathbf{n} / \mathbf{a}$ & $\mathbf{n} / \mathbf{a}$ \\
\hline 4 & - & + & - & - & atrophy & normal \\
\hline 5 & + & - & - & + & $\mathbf{n} / \mathbf{a}$ & $\mathrm{n} / \mathrm{a}$ \\
\hline 6 & + & - & + & - & $\begin{array}{l}\text { atrophy, especially } \\
\text { frontal }\end{array}$ & $\begin{array}{l}\text { bilateral frontal } \\
L>R\end{array}$ \\
\hline 7 & - & + & - & - & $\begin{array}{l}\text { atrophy, especially } \\
\text { frontal }\end{array}$ & $\begin{array}{l}\text { bilateral frontal } \\
L>R\end{array}$ \\
\hline 8 & - & - & + & - & $\begin{array}{l}\text { atrophy } \\
\text { (MRI especially temporal) }\end{array}$ & $\begin{array}{l}\text { bilateral frontal } \\
L>R\end{array}$ \\
\hline 9 & + & - & - & + & $\mathrm{n} / \mathrm{a}$ & $\mathbf{n} / \mathbf{a}$ \\
\hline 10 & + & - & - & + & atrophy & anterior subcortical \\
\hline 11 & + & - & - & + & atrophy & normal \\
\hline 12 & + & - & + & - & $\begin{array}{l}\text { atrophy, especially } \\
\text { frontal }\end{array}$ & $\mathrm{L}$ frontal \\
\hline
\end{tabular}

Figure 1 Coronal section of brain from patient 5 at levels of the frontal cortex (a) and corpus striatum (b) showing the severe atrophy of the frontal and temporal lobes and gross enlargement of the lateral ventricle. (a) $\times 1.4$; (b) $\times 1$. against amyloid $(\beta / \mathrm{A} 4)$ protein $(1 / 200),{ }^{13}$ tau protein (1/500) (Sigma), ubiquitin (1/500) (Dako), and glial fibrillary acidic protein, GFAP (1/750) (Sigma).

\section{Results}

GENERAL NEUROPATHOLOGICAL CHANGES

Patients 1-8

In these patients the brain weight (where recorded) was grossly reduced, ranging from 870-1130 g. The cerebral cortex was atrophied, this being present to varying degrees throughout the entire hemisphere but usually most severe within, and sometimes restricted to, frontal lobes, frontoparietal cortex, and anterior temporal lobe (figs $1 \mathrm{a}, \mathrm{b}$ ) (table 3). A moderate or severe atrophy of the hippocampus, amygdala, and corpus striatum (fig 1b) was often also present. The globus pallidus, thalamus, mid brain, brainstem, and cerebel- lum were usually normal or only mildly atrophied. The lateral ventricles were usually grossly enlarged particularly anteriorly (fig 1b) as were the temporal horns. The major cerebral arteries were either unaffected, or only minimally affected, by atheroma with no evidence of cerebral infarction.

The histopathological changes within affected areas of the cerebral cortex were characterised by a severe (and sometimes almost total) loss of nerve cells, particularly from cortical layers II and III but also affecting to a lesser extent those of layer $\mathrm{V}$ (figs 2ad). Remaining cells in layers III and V were usually shrunken, though in patient 6 an occasional swollen neuron (that is, a "ballooned Pick cell") was noted. In patients 1-4 a pronounced spongiform change, mainly affecting layer II, was seen (fig $2 a$ ). A reactive astrocytosis was present in all patients that, while affecting all cortical layers to some
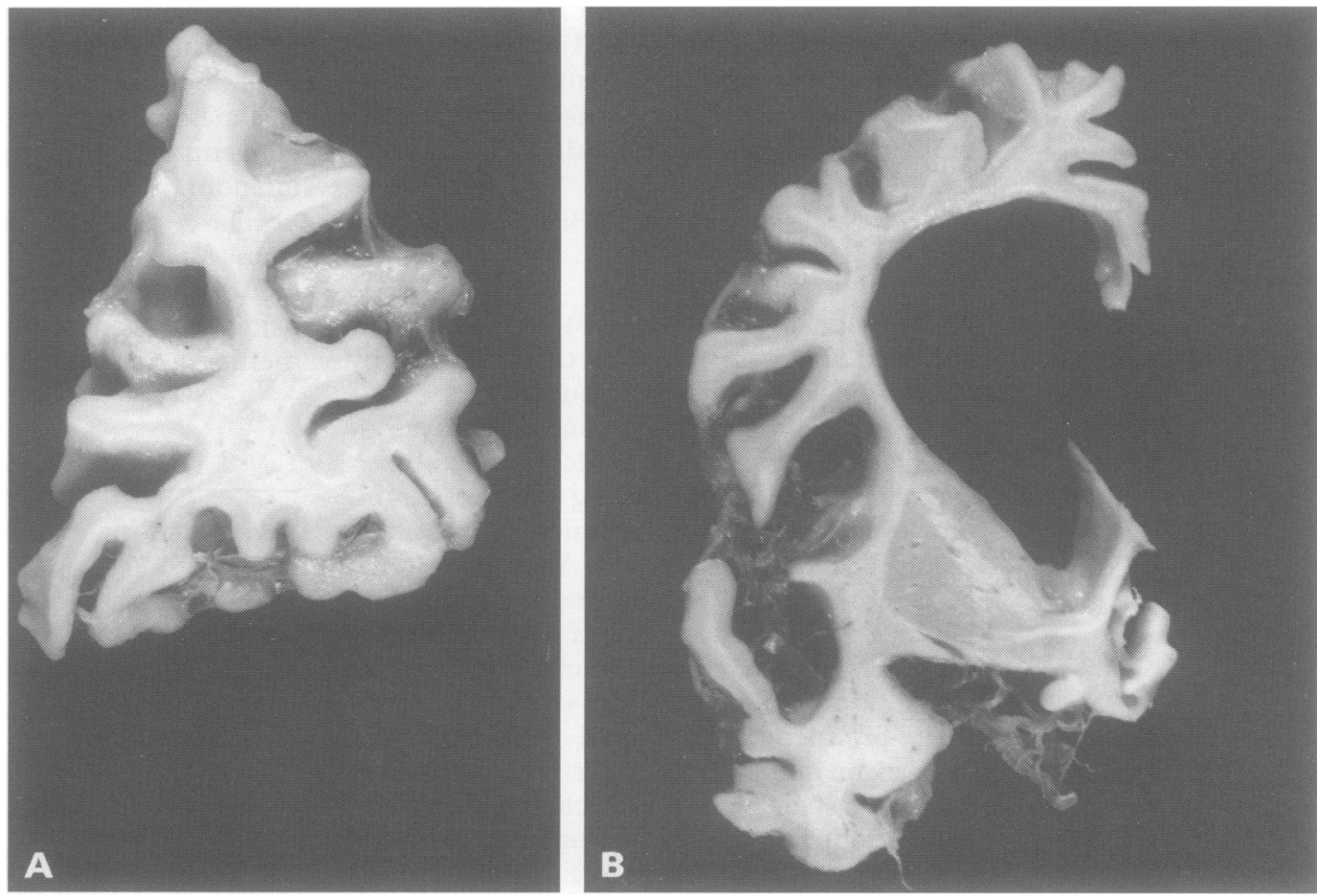
Table 3 Topographic distribution of atrophy within the brains of patients 1-12

\begin{tabular}{|c|c|c|c|c|c|c|c|c|c|c|c|}
\hline $\begin{array}{l}\text { Patient } \\
\text { No }\end{array}$ & $\begin{array}{l}\text { Brain } \\
\text { weight } \\
\text { (g) }\end{array}$ & Frontal & $\begin{array}{l}\text { Anterior } \\
\text { temporal (plus) } \\
\text { entorhinal) }\end{array}$ & $\begin{array}{l}\text { Posterior } \\
\text { temporal }\end{array}$ & $\begin{array}{l}\text { Anterior } \\
\text { parietal }\end{array}$ & $\begin{array}{l}\text { Posterior } \\
\text { parietal }\end{array}$ & Occipital & Hippocampus & Amygdala & Striatum & $\begin{array}{l}\text { Cerebellum } \\
\text { brain } \\
\text { stem }\end{array}$ \\
\hline $\begin{array}{r}1 \\
2 \\
3 \\
4 \\
5 \\
6 \\
7 \\
8 \\
9 \\
10 \\
11 \\
12\end{array}$ & $\begin{array}{l}1016 \\
955 \\
900 \\
1130 \\
870 \\
1110 \\
\mathrm{n} / \mathrm{a} \\
\mathrm{n} / \mathrm{a} \\
1115 \\
1160 \\
1290 \\
1270\end{array}$ & $\begin{array}{l}+++ \\
+++ \\
+++ \\
+ \\
+++ \\
+++ \\
+++ \\
++ \\
+ \\
++ \\
++ \\
++\end{array}$ & $\begin{array}{l}+++ \\
+++ \\
+++ \\
++ \\
+++ \\
+++ \\
+++ \\
+++ \\
+++ \\
++ \\
++ \\
+\end{array}$ & $\begin{array}{l}++ \\
++ \\
++ \\
+ \\
++ \\
++ \\
++ \\
++ \\
++ \\
++ \\
++ \\
+\end{array}$ & $\begin{array}{l}++ \\
+++ \\
+++ \\
+ \\
+++ \\
++ \\
++ \\
++ \\
++ \\
+ \\
++ \\
+\end{array}$ & $\begin{array}{l}+ \\
++ \\
++ \\
+ \\
++ \\
+ \\
+ \\
+ \\
+ \\
0 \\
+ \\
0\end{array}$ & $\begin{array}{l}+ \\
++ \\
+ \\
+ \\
+ \\
+ \\
+ \\
+ \\
+ \\
0 \\
+ \\
0\end{array}$ & $\begin{array}{l}++ \\
+++ \\
++ \\
0 \\
++ \\
++ \\
++ \\
+ \\
+++ \\
++ \\
++ \\
0\end{array}$ & $\begin{array}{l}++ \\
+++ \\
++ \\
++ \\
+++ \\
+++ \\
+++ \\
+++ \\
+++ \\
++ \\
++ \\
0\end{array}$ & $\begin{array}{l}++ \\
++ \\
++ \\
+ \\
++ \\
++ \\
++ \\
+ \\
+++ \\
+++ \\
+++ \\
++\end{array}$ & $\begin{array}{l}0 \\
+ \\
0 \\
0 \\
+ \\
0 \\
0 \\
0 \\
0 \\
0 \\
0 \\
0\end{array}$ \\
\hline
\end{tabular}

$0=$ no atrophy; $+=$ mild atrophy; $++=$ moderate atrophy; $+++=$ severe atrophy.
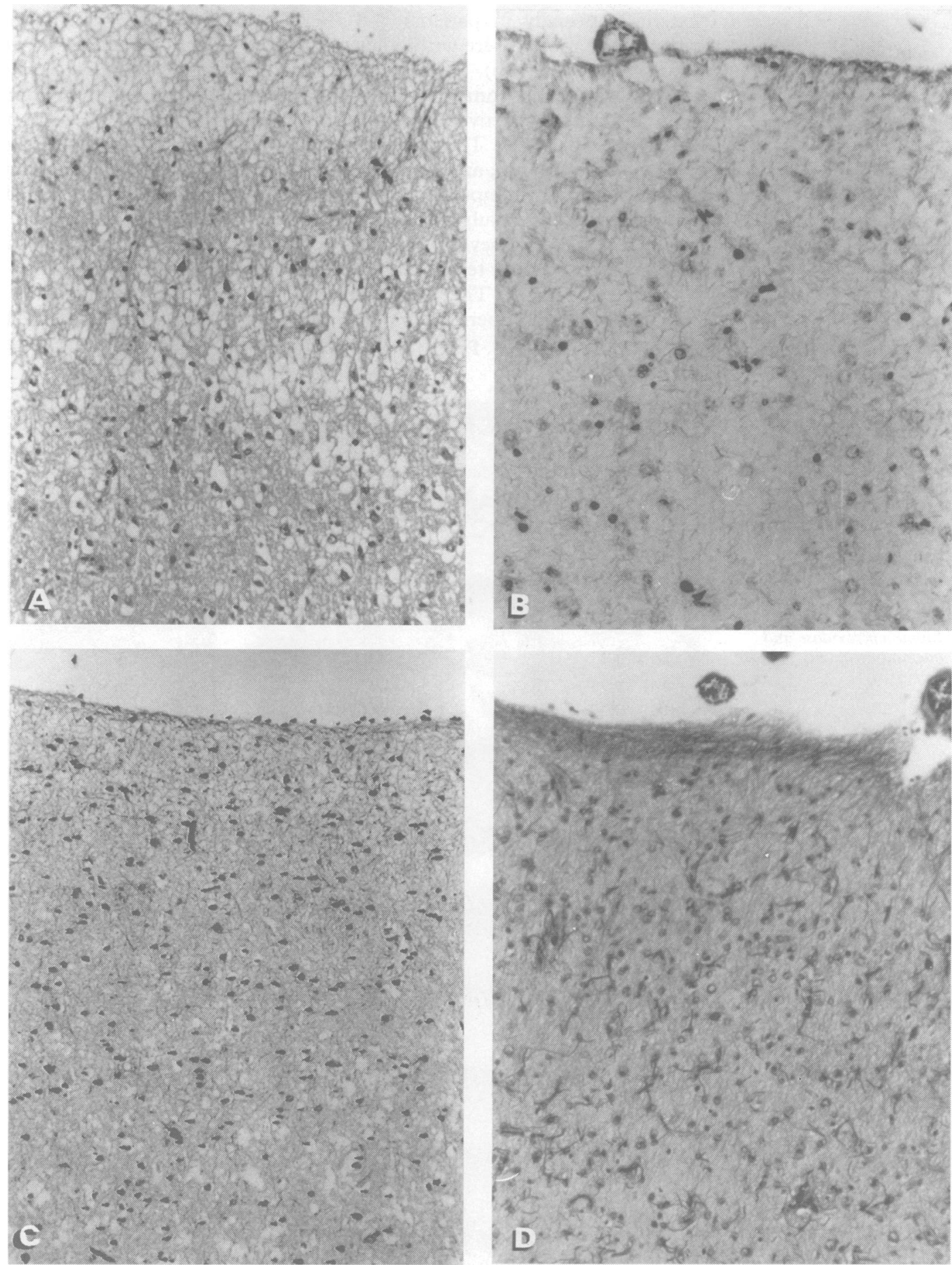

Figure 2 Histological changes in the frontal cortex of patient 1 (a) and (b), and patient 5 (c) and (d). In patient 1 there is a prominent spongiform change in layer II (a) with only a mild and mostly subpial gliosis (b). In patient 5 there is little, if any, spongiosus (c) though a florid astrocytosis affecting all cortical layers is present (d). (a), (c) Weigert's haematoxylin and eosin, (b), (d) Phosphotungstic acid and haematoxylin. All $\times 114$. 
Table 4 Topographic distribution of histological changes within the brains of patients 1-12

\begin{tabular}{|c|c|c|c|c|c|c|c|c|c|c|c|c|c|c|c|c|}
\hline \multirow{2}{*}{$\begin{array}{l}\text { Patient } \\
\text { No }\end{array}$} & \multirow{2}{*}{$\begin{array}{l}\text { Areas } \\
\text { grossly } \\
\text { affected }\end{array}$} & \multicolumn{3}{|c|}{ Cerebral Cortex } & \multicolumn{3}{|c|}{ Hippocampus } & \multicolumn{3}{|c|}{ Amygdala } & \multicolumn{3}{|c|}{ Striatum } & \multicolumn{3}{|c|}{ Substantia nigra } \\
\hline & & $N C L$ & $S C$ & $G$ & $N C L$ & $S C$ & $G$ & $N C L$ & $S C$ & $G$ & $N C L$ & $S C$ & $G$ & $N C L$ & $S C$ & $G$ \\
\hline $\begin{array}{r}1 \\
2 \\
3 \\
4 \\
5 \\
6 \\
7 \\
8 \\
9 \\
10 \\
11 \\
12\end{array}$ & $\begin{array}{l}\text { F, AT, AP, S } \\
\text { F, AT, AP, S } \\
\text { F, AT, AP, S } \\
\text { F, AT } \\
\text { F, AT, AP, S } \\
\text { F, AT, AP, S } \\
\text { F, AT, AP, S } \\
\text { F, AT, AP, S } \\
\text { AT, PT, S } \\
\text { F, AT, PT, S } \\
\text { F, AT, AP, S } \\
\text { F, AT, AP, S }\end{array}$ & $\begin{array}{l}+++ \\
+++ \\
+++ \\
++ \\
+++ \\
+++ \\
+++ \\
+++ \\
+++ \\
+ \\
+++ \\
++\end{array}$ & $\begin{array}{l}+++ \\
++ \\
+++ \\
+ \\
+ \\
+ \\
+ \\
+ \\
0 \\
0 \\
0 \\
++\end{array}$ & $\begin{array}{l}+ \\
+++ \\
+ \\
+ \\
+++ \\
+++ \\
+++ \\
+++ \\
+++ \\
+ \\
+++ \\
+\end{array}$ & $\begin{array}{l}0 \\
+ \\
++ \\
0 \\
++ \\
0 \\
+ \\
0 \\
+++ \\
+++ \\
+++ \\
0\end{array}$ & $\begin{array}{l}0 \\
0 \\
0 \\
0 \\
0 \\
0 \\
0 \\
0 \\
0 \\
0 \\
0 \\
0\end{array}$ & $\begin{array}{l}+ \\
++ \\
++ \\
0 \\
+ \\
0 \\
0 \\
+ \\
+++ \\
+++ \\
+++ \\
++\end{array}$ & $\begin{array}{l}0 \\
+ \\
+ \\
0 \\
++ \\
0 \\
+ \\
+ \\
+++ \\
++ \\
++ \\
0\end{array}$ & $\begin{array}{l}0 \\
0 \\
0 \\
0 \\
0 \\
0 \\
0 \\
0 \\
0 \\
0 \\
0 \\
0\end{array}$ & $\begin{array}{l}+ \\
+ \\
+ \\
0 \\
++ \\
+ \\
+ \\
+ \\
+++ \\
+++ \\
++ \\
++\end{array}$ & $\begin{array}{l}+++ \\
+ \\
+ \\
0 \\
0 \\
0 \\
0 \\
+ \\
++ \\
+++ \\
+++ \\
0\end{array}$ & $\begin{array}{l}+ \\
0 \\
0 \\
0 \\
0 \\
0 \\
0 \\
0 \\
0 \\
0 \\
0 \\
0\end{array}$ & $\begin{array}{l}+ \\
+ \\
+ \\
0 \\
++ \\
+ \\
++ \\
++ \\
++ \\
+++ \\
+++ \\
+\end{array}$ & $\begin{array}{l}0 \\
0 \\
++ \\
0 \\
+++ \\
0 \\
0 \\
0 \\
0 \\
+++ \\
0 \\
+++\end{array}$ & $\begin{array}{l}0 \\
0 \\
0 \\
0 \\
0 \\
0 \\
0 \\
0 \\
0 \\
0 \\
0 \\
0\end{array}$ & $\begin{array}{l}0 \\
0 \\
0 \\
0 \\
++ \\
0 \\
0 \\
0 \\
0 \\
+++ \\
0 \\
+++\end{array}$ \\
\hline
\end{tabular}

$\mathrm{F}=$ frontal lobe; $\mathrm{AT}=$ anterior temporal lobe; $\mathrm{PT}=$ posterior temporal lobe; $\mathrm{AP}=$ anterior parietal lobe; $\mathrm{S}=$ striatum; $\mathrm{NCL}=\mathrm{nerve}$ cell loss; $\mathrm{SC}=$ spongiform

change; $\mathrm{G}=$ gliosis.

extent (especially in patients 5-8 (fig 2d)), was usually most severe within layers I-II and layers V-VI (fig 2b). Considerable loss of myelin and axons from the white matter was seen and a mild reactive astrocytosis was also usually present here. The changes were most severe within frontal, anterior temporal (middle and inferior temporal gyri), entorhinal, anterior parietal, insular, and cingulate cortices, decreasing in severity in posterior parietal and posterior temporal (middle and inferior gyri) cortex. They were usually minimal or absent in superior temporal gyrus (at all levels), pre and post central gyri, and

Figure 3 Inclusions (arrowed) within the hippocampus (a) and (c), and frontal cortex (b) and (d) of patient 6. These are argyrophilic (a) and (b) and also immunoreactive with antisera to human tau proteins (c) and $(d)$ and ubiquitin (not shown). (a), (b) Palmgren silver stain. (c), (d)

Immunoperoxidase and haematoxylin. All $\times 475$.
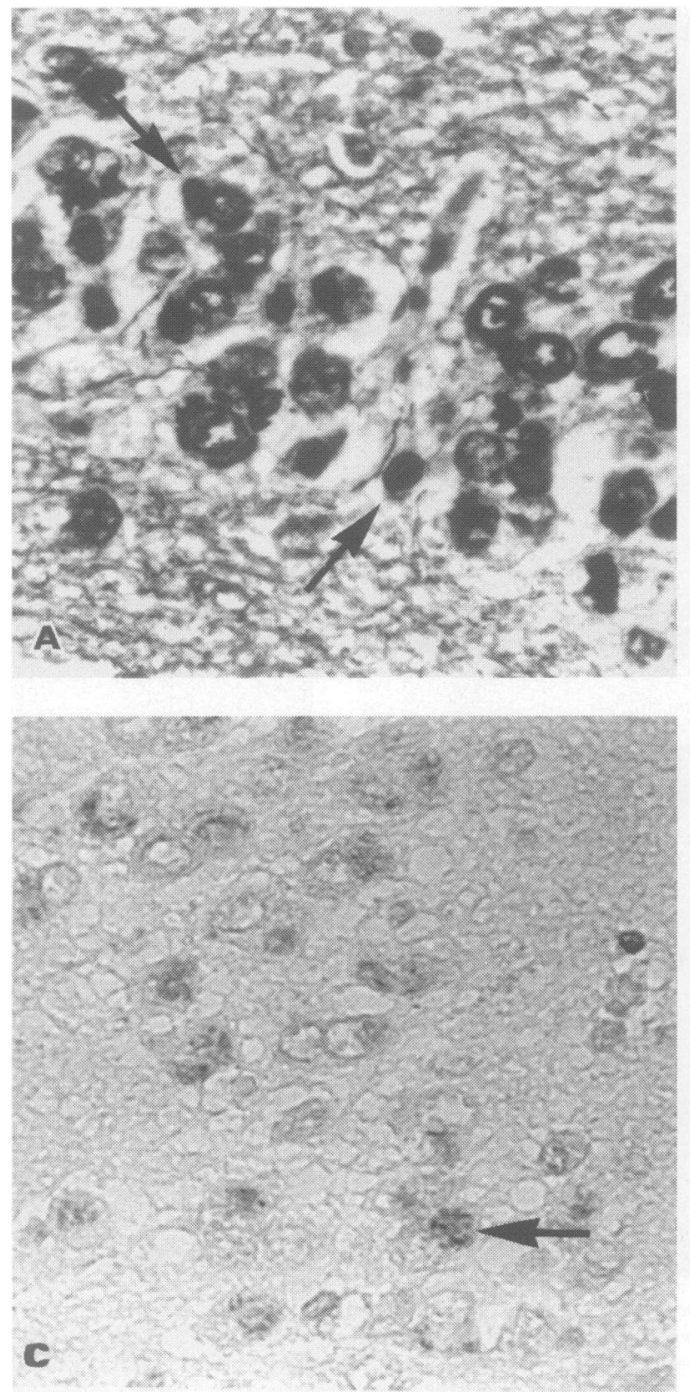

occipital (including calcarine) cortex. Although all eight patients showed these three histopathological features (that is, nerve cell loss, spongiform change, gliosis) the emphasis varied between patients with patients 1-4 showing a moderate to severe spongiform change with mild gliosis (fig $2 \mathrm{a}, \mathrm{b}$ ) whereas patients 5-8 showed a minimal spongiform change with intense gliosis (fig 2c, d); severe nerve cell loss was common to all eight patients (table 4).

In patients $2,3,5,7$ a variable loss of nerve cells from CA1, CA4/5, and subiculum of the hippocampus and the basolateral nuclei
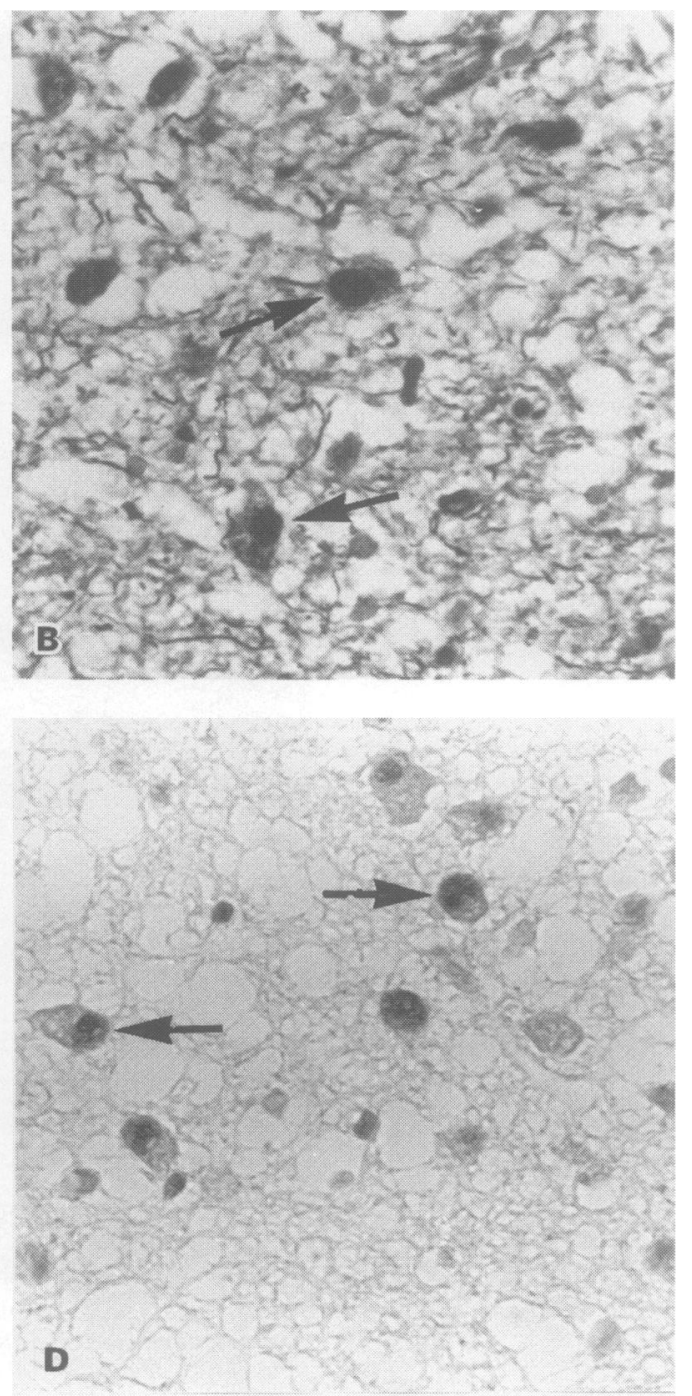
of the amygdala had taken place together with a similar level of gliosis (table 4). In the other patients these regions showed either no obvious changes or a mild gliosis in areas CA4/5 alone (for example, patients 1 and 8). Argyrophilic inclusions were noted in the granule cells in the dentate gyrus of the hippocampus (fig 3a) and within neurons of the frontal cortex (fig 3b) in patients 6 and 7 . Although the corpus striatum was grossly atrophied in many patients (table 3), histologically this area usually appeared normal except for a mild or moderate gliosis in patients $1,2,3,5,6,7$, and 8 ; only in patients 1 and 2 did there appear to be any significant neuronal loss and only in patient 1 was there any spongiform change. The thalamus and globus pallidus were normal in all patients. In most patients the nucleus basalis appeared normal though in patients 1 and 2 some shrinkage and loss of nerve cells had occurred. The cerebellum and brainstem (particularly the hypoglossal nucleus) were histologically normal in all except patients 3 and 5 where some loss of cells from the substantia nigra had occurred which, in patient 5 , was accompanied by a reactive gliosis.

\section{Patients 9-11}

Patients 9-11 showed less overall reduction in brain weight (1115-1290 g) than patients 1-8 (table 3) but displayed more variable patterns of atrophy. In patient 9, atrophy was focused upon the temporal lobe (including the hippocampus and amygdala) and striatum whereas in patients 10 and 11 (fig 4a) atrophy was most severe within the striatum (and globus pallidus and thalamus) with frontal or temporal lobes respectively being only moderately affected. In all three patients the cerebellum and brainstem appeared macroscopically normal. The lateral ventricles were grossly dilated anteriorly (fig $4 \mathrm{a}$ ) as were the temporal horns. The major cerebral arteries were free from atheroma in all three patients.

In general histopathological terms, patients 9-11 also showed a loss of large cortical nerve cells, gliosis, and spongiform change, though the distribution and balance of these varied (table 4). In patient 9, nerve cell loss and gliosis were profound in all parts of the temporal cortex (including the entorhinal cortex), hippocampus and amygdala, whereas the frontal and anterior parietal cortices were only mildly affected; the posterior parietal and occipital cortex were unaffected. In patient 10 , the frontal cortex was only mildly affected and all other cortical regions were histologically normal; however the hippocampus, entorhinal cortex, and amygdala were
Figure 4 Changes in the brain of patient 11. On coronal section (a) there is severe atrophy of the striatum with moderate atrophy of the temporal lobe. Histologically the frontal cortex shows spongiform change (b) with severe nerve cell loss and intense gliosis within the caudate nucleus (c). (a) $\times 0.9 ;$ (b), (c) Weigert's

haematoxylin-eosin; $\times 114$
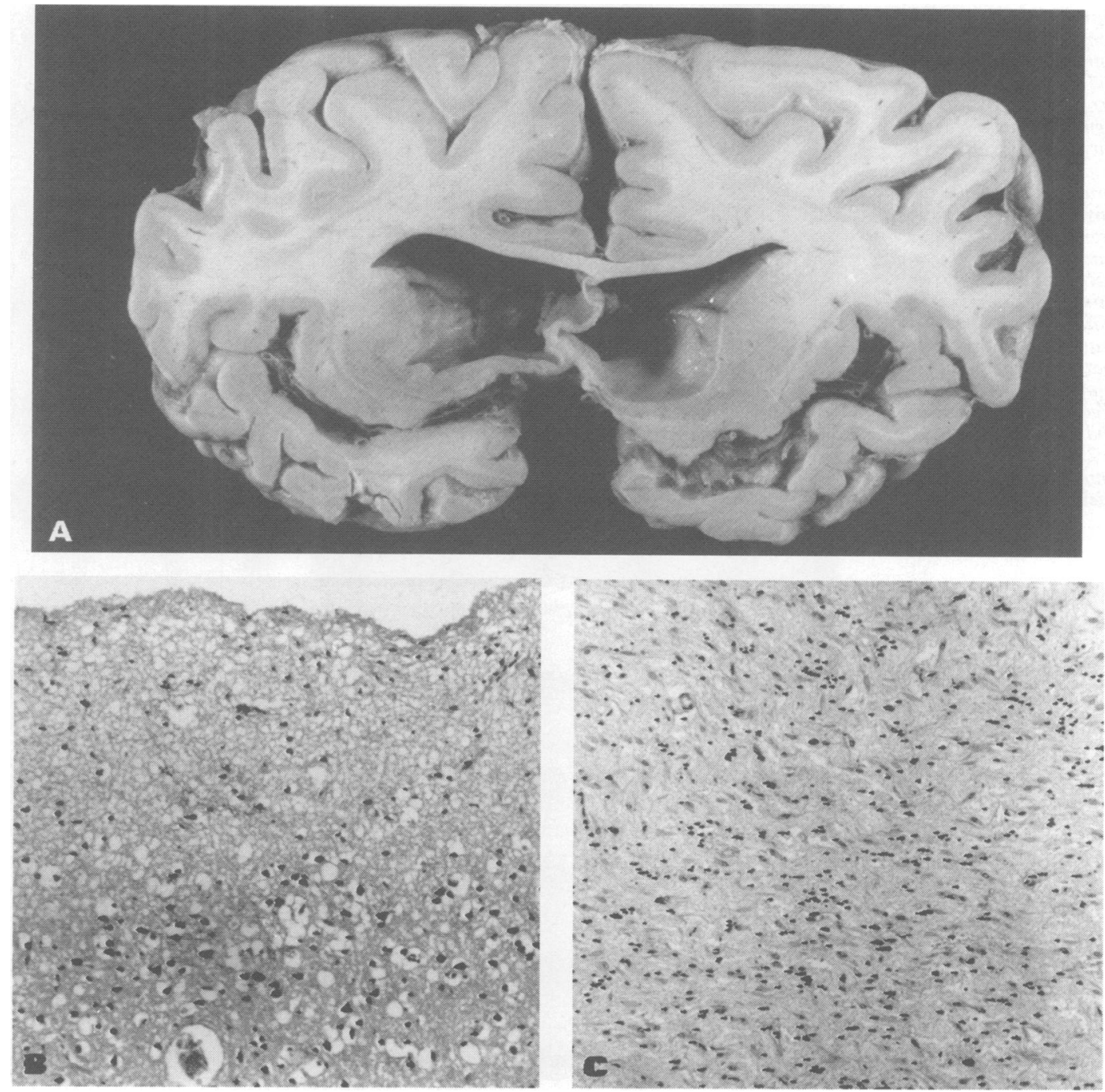
severely affected throughout all subregions. In patient 11 , the frontal cortex (fig $4 \mathrm{~b}$ ), but not other cortical regions, was affected together with the hippocampus (including entorhinal cortex) and amygdala. In all three patients the corpus striatum was the region most severely damaged, showing a virtually complete loss of nerve cells from both caudate nucleus and putamen with intense gliosis (fig 4c). The globus pallidus was affected in patient 11 though the thalamus was histologically normal in all except patient 10 where a mild gliosis was present in medial thalamus. The substantia nigra showed a severe loss of nerve cells with intense gliosis in patient 10 , but was normal in patients 9 and 11. The cerebellum and other brainstem regions (including the hypoglossal nucleus) were normal in all patients.

\section{Patient 12}

The brain weight (1270 g) was only slightly reduced, cortical atrophy was mild and confined to frontal and frontoparietal regions. The corpus striatum was moderately atrophic and the thalamus and globus pallidus were slightly smaller than usual. The lateral ventricles, including the temporal horn extensions, were moderately enlarged. The substantia nigra was poorly pigmented. Histologically, a similar, though milder, type of change to that seen in patients 1-4 was present in the frontal, frontoparietal, and anterior temporal regions - that is, loss of large cortical nerve cells, spongiform degeneration of layer II, and gliosis within layers I-II and layers V-VI (fig 5a). Apart from a moderate gliosis within the end folium and the basolateral nuclei respectively the hippocampus and amygdala appeared normal. The substantia nigra (fig 5b) and globus pallidus showed an almost complete loss of nerve cells and both displayed a dense reactive gliosis; only a slight gliosis was seen in the corpus striatum. All cranial nerve nuclei appeared normal and the corticospinal tract, like all other white matter areas, appeared well myelinated.

\section{Immunohistochemistry}

Only in patient 4 were any deposits of amyloid ( $\beta / A 4)$ protein detected, these deposits being present as "diffuse" plaques sparsely distributed throughout the whole of the neocortex; none were associated with a neuritic change and no neurofibrillary tangles were detected in nerve cell perikarya in this or in any other patient.
Figure 5 Histological changes in patient 12. The frontal cortex (a) shows spongiform degeneration and the substantia nigra (b) shows severe loss of pigmented nerve cells with intense gliosis. Nerve cells of layer II of the frontal cortex contain inclusions (arrowed) that display strong anti-ubiquitin immunoreactivity (c) and there is also much particulate or thread-like material within the neuropil (d) (arrowed) that is also ubiquitin immunoreactive. (a), (b) Weigert's haematoxylin and eosin; $\times 110(a)$, $\times 230$ (b). (c), (d) Immunoperoxidase and haematoxylin; $\times 450$.
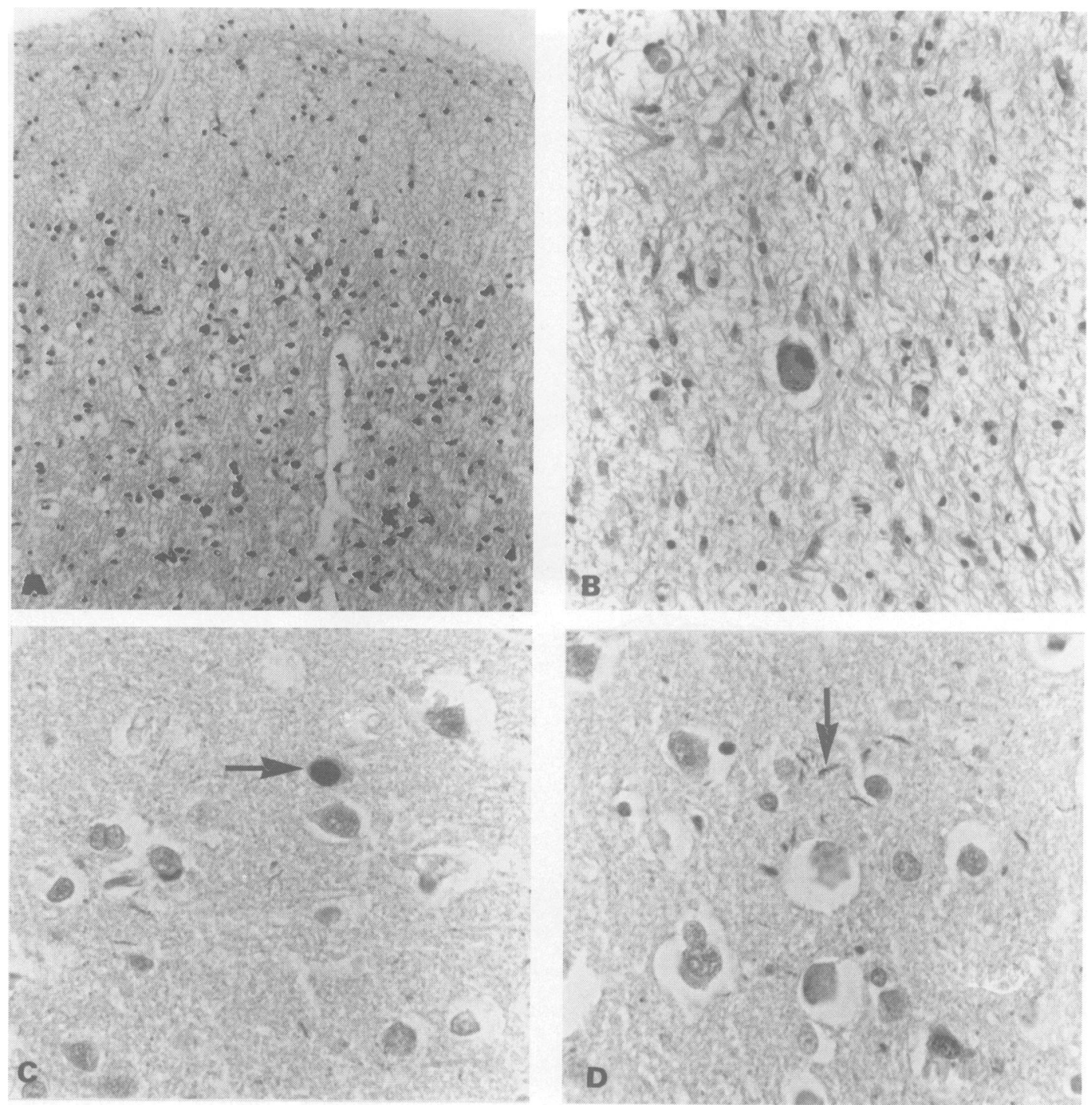
Table 5 Topographical distribution of immunohistochemical changes within the brains of patients 1-12

\begin{tabular}{|c|c|c|c|c|c|c|c|c|c|c|c|c|c|c|c|c|c|c|}
\hline \multirow[b]{2}{*}{$\begin{array}{l}\text { Patient } \\
\text { No }\end{array}$} & \multicolumn{6}{|c|}{ Cerebral Cortex } & \multicolumn{3}{|c|}{ Hippocampus } & \multicolumn{3}{|c|}{ Amygdala } & \multicolumn{3}{|c|}{ Striatum } & \multicolumn{3}{|c|}{ Substantia nigra } \\
\hline & $\underset{G}{a t a u}$ & $W$ & $\underset{G}{a u b i}$ & $W$ & $\underset{G}{a} G F A P$ & $\stackrel{a}{W}$ & $\begin{array}{l}a \\
\text { tau }\end{array}$ & $\begin{array}{l}a \\
u b i\end{array}$ & $\stackrel{a}{G F A P}$ & $\begin{array}{l}a \\
\text { tau }\end{array}$ & $\begin{array}{l}a \\
u b i\end{array}$ & $\stackrel{a}{G F A P}$ & $\begin{array}{l}a \\
\text { tau }\end{array}$ & $\begin{array}{l}a \\
u b i\end{array}$ & $\stackrel{a}{G F A P}$ & $\begin{array}{l}a \\
\text { tau }\end{array}$ & $\begin{array}{l}a \\
u b i\end{array}$ & $G F A P$ \\
\hline 1 & + & + & $0 /+$ & + & ++ & + & $0 /+$ & $0 /+$ & ++ & $0 /+$ & $0 /+$ & + & $0 /+$ & $0 /+$ & + & 0 & 0 & 0 \\
\hline 2 & $0 /+$ & 0 & $0 /+$ & 0 & +++ & + & $0 /+$ & 0 & ++ & $0 /+$ & 0 & + & 0 & 0 & + & 0 & 0 & 0 \\
\hline 3 & 0 & 0 & $0 /+$ & 0 & +++ & + & 0 & 0 & + & 0 & 0 & + & 0 & 0 & + & 0 & 0 & 0 \\
\hline 4 & 0 & 0 & 0 & + & ++ & + & 0 & 0 & + & 0 & 0 & 0 & 0 & 0 & 0 & 0 & 0 & 0 \\
\hline 5 & 0 & ++ & 0 & +++ & +++ & 0 & 0 & 0 & ++ & 0 & 0 & ++ & 0 & 0 & ++ & 0 & 0 & ++ \\
\hline 6 & +++ & 0 & ++ & ++ & ++ & 0 & ++ & ++ & + & + & 0 & + & + & 0 & + & 0 & 0 & 0 \\
\hline 7 & ++ & 0 & + & ++ & +++ & 0 & ++ & 0 & + & + & 0 & + & + & 0 & ++ & 0 & 0 & 0 \\
\hline 8 & $0 /+$ & 0 & + & + & +++ & 0 & $0 /+$ & $0 /+$ & + & $0 /+$ & 0 & + & 0 & 0 & ++ & 0 & 0 & 0 \\
\hline 9 & 0 & 0 & 0 & 0 & +++ & 0 & 0 & 0 & ++ & 0 & 0 & +++ & 0 & 0 & +++ & 0 & 0 & 0 \\
\hline 10 & 0 & 0 & 0 & 0 & ++ & + & 0 & 0 & ++ & 0 & 0 & +++ & 0 & 0 & +++ & 0 & 0 & +++ \\
\hline 11 & 0 & +++ & 0 & +++ & ++ & + & 0 & 0 & ++ & 0 & 0 & ++ & 0 & 0 & +++ & 0 & 0 & 0 \\
\hline 12 & + & ++ & ++ & +++ & ++ & +++ & 0 & 0 & ++ & + & + & ++ & + & + & + & ++ & ++ & +++ \\
\hline
\end{tabular}

$\mathrm{G}=$ grey matter; $\mathrm{W}=$ white matter; ubi = ubiquitin; GFAP = glial fibrillary acidic protein; tau = microtubule associated protein, tau

$0=$ absent $; 0 /+=$ found only after intensive search $+=$ mild; $++=$ moderate $+++=$ severe .

Anti-tau and anti-ubiquitin immunohistochemistry showed widely differing patterns of staining, failing to reveal changes common to all, or even most, patients (table 5) with distinctive changes being demonstrated only in patients 6,7 , and 12 . In patient 6 most surviving nerve cells within layer II of the frontal cortex, anterior temporal cortex, and entorhinal cortex displayed a strong anti-tau immunoreactivity; many nerve cells in layers III and $\mathrm{V}$ also showed this change. The taustaining appeared mostly diffuse and granular though sometimes well defined inclusions were seen (fig 3d). Many of the tau positive cells and inclusions were also detected, though less strongly, with anti-ubiquitin. The white matter showed a pronounced granularity with anti-ubiquitin but not with anti-tau. This granularity of white matter staining with anti-ubiquitin is seen in other neurodegenerative diseases (for example, Alzheimer's disease, Mann unpublished observations) and increases with age in non-demented individuals $^{14}$; it may represent a non-specific phenomenon (in disease terms) which is related to axonal loss or degeneration. These kinds of cortical change were less prominent within anterior parietal and posterior temporal regions, being absent in posterior parietal and occipital cortices. In the hippocampus many granular neurons of the dentate gyrus (fig 3c) and pyramidal neurons within areas CAl and subiculum showed strong anti-tau immunoreactivity that was again granular in nature with clearly defined inclusions only occasionally seen. These same cell types were also stained, but again less strongly, using anti-ubiquitin. In the amygdala and corpus striatum occasional cells were stained with anti-tau (but not anti-ubiquitin), in a diffuse and granular manner without formation of inclusions. Similar, though less extensive, changes to these were seen in patient 7 (table 5).

In patient 12 a moderate number of nerve cells within frontal and anterior temporal cortex showed a strong reaction with anti-ubiquitin with staining being either diffusely granular or occasionally present as well defined rounded inclusions (fig 5c). Much particulate material was present within the neuropil often with a "thread"-like appearance (fig 5d). Anti-tau immunostaining revealed a similar though much less intense pattern of staining. Much granular material was present in the white matter (see above). Occasional nerve cells in the amygdala and striatum and nearly all surviving cells within the substantia nigra displayed a diffuse antitau and anti-ubiquitin immunoreactivity.

In patients 1,2 , and 8 occasional nerve cells in the cerebral cortex, hippocampus (dentate gyrus, CA1) amygdala, and striatum showed a weak granular reaction with both anti-tau and anti-ubiquitin but no inclusions were seen. In patients $1,4,5,8$, and 11 the frontal and temporal cortical white matter showed a diffuse granularity that was antiubiquitin (and in patients 1 and 5 anti-tau) positive. In patient 3 much fine particulate and thread-like material that was anti-ubiquitin (but not anti-tau) positive was seen in grey (but not white) matter of frontal and temporal cortex. Patients 9 and 10 were entirely unreactive with either anti-tau or antiubiquitin.

In all 12 patients, affected regions of brain showed an increased cerebral cortical GFAP immunoreactivity within reactive astrocytes. Three patterns of gliosis were noted. In one (patients 1, 2, 3, 4, 9, 11, and 12) astrocytosis was mild overall but most prevalent in layers I-II and layer VI, being sparse in layers III-V and in white matter; patient 12 showed similar grey matter changes, but with a heavy white matter gliosis whereas patient 9 showed no white matter changes. In the second (patients 5, 6, 7, and 8), a heavy gliosis of layers I-II was seen, with all other layers being equivalently, but slightly less, affected; there were no white matter changes. Patient 10 showed an idiosyncratic pattern with a moderate gliosis present in layers I, III, V-VI, and white matter, but no gliosis within layers II and IV. All 12 patients showed a mild to moderate gliosis within the hippocampus that affected either the end folium alone (patients 4, 6, 8, and 12), CA1 and subiculum alone (patient 7), or both (patients $1,2,3,5,9,10,11$ ) according to whether and to what extent nerve cell loss had occurred. Gliosis was also diffusely seen throughout the amygdala and striatum (especially caudate nucleus) in all except patient 4, though only in patients 9,10 , and 11 was this severe. A moderate to severe gliosis was 
Table 6 Topographical summation of gross, histological, and immunohistological changes in the brains of patients 1-12

\begin{tabular}{|c|c|c|c|c|c|c|}
\hline Patient No & Frontal & Temporal & Limbic & Striatal & Nigral & Cerebellar \\
\hline $\begin{array}{r}1 \\
2 \\
3 \\
4 \\
5 \\
6 \\
7 \\
8 \\
9 \\
10 \\
11 \\
12\end{array}$ & $\begin{array}{l}+++ \\
+++ \\
+++ \\
+ \\
+++ \\
+++ \\
+++ \\
+++ \\
0 \\
+ \\
+++ \\
++\end{array}$ & $\begin{array}{l}++ \\
++ \\
+++ \\
+ \\
+++ \\
+++ \\
++ \\
+++ \\
+++ \\
0 \\
++ \\
0\end{array}$ & $\begin{array}{l}0 \\
+ \\
++ \\
0 \\
++ \\
++ \\
++ \\
+ \\
+++ \\
+++ \\
++ \\
+\end{array}$ & $\begin{array}{l}++ \\
++ \\
++ \\
0 \\
+ \\
++ \\
++ \\
+ \\
+++ \\
+++ \\
+++ \\
++\end{array}$ & $\begin{array}{l}0 \\
0 \\
++ \\
0 \\
+++ \\
0 \\
0 \\
0 \\
0 \\
+++ \\
0 \\
+++\end{array}$ & $\begin{array}{l}0 \\
0 \\
0 \\
0 \\
0 \\
0 \\
0 \\
0 \\
0 \\
0 \\
0 \\
0\end{array}$ \\
\hline
\end{tabular}

$0=$ absent; $+=$ mild; $++=$ moderate; $+++=$ severe.

seen within the substantia nigra in patients 5 , 10 and 12 .

\section{Summary of results}

The topographical distribution of the gross, histological and immunohistochemical pathologies and their severity is presented for all 12 patients in table 6 . It is clear that the clinical syndrome that we have termed dementia of frontal lobe type ${ }^{16}$ is pathologically heterogeneous and appears to comprise several distinctive subgroups.

The first subgroup (type A) (patients 1-4) is characterised by a frontotemporal atrophy defined histologically by a loss of large cortical nerve cells, a spongiform degeneration of the superficial neuropil, and a minimal and restricted gliosis. No distinctive changes (swellings or inclusions) within remaining nerve cells are seen. The limbic system and the striatum are affected but to a much lesser extent.

The second subgroup (type B) (patients 5-8) is also characterised by a frontotemporal atrophy but which is defined by a loss of large cortical nerve cells with widespread and abundant gliosis but minimal or no spongiform change. Swollen neurons or inclusions that are both tau and ubiquitin positive are sometimes typically present in some patients and the limbic system and striatum are more seriously damaged.

In the third subgroup (type C) (patients 9-11) the brunt of the pathology is borne by the striatum with (usually) severe limbic involvement but variable cortical and nigral involvement. Immunohistochemistry reveals no significant changes.

In the last subgroup (type D) the atrophy is mostly frontal, with some temporal involvement, characterised by loss of large cortical nerve cells, spongiform change, and mild gliosis; limbic involvement is slight, though nigral damage is severe. Ubiquitinated inclusions are present within the frontal cortex.

\section{CLINICOPATHOLOGICAL RELATIONSHIPS}

These four groupings are based on the morphological characteristics of brains retrieved from patients who in life had undergone longitudinal neuropsychological analysis and brain imaging. These clinical data were examined retrospectively and compared with the pathological findings in order to determine any salient clinicopathological relationships.

\section{Demographic features}

There were no group differences with respect to age of onset, duration of illness, or patient gender (table 1). However, the presence of a family history of dementia in a first degree relative characterised group $A$, whereas in group B there was an absence of a family history in most instances. There was a positive family history in one of the three patients in group $\mathrm{C}$, but none in the patient in group D.

\section{Clinical syndromes}

All patients showed those features associated with dementia of frontal lobe type ${ }^{1}$ (table 2) - that is, profound personality change and social misconduct followed by progressive language impairment. Nevertheless, significant clinical distinctions emerged in group C patients where a stereotyped behaviour represented the dominant clinical feature. Whereas overeating and food fadism occurred in all patients, hyperorality, with the mouthing of inanimate objects, was an early characteristic of group C only. With progression of disease all patients developed neurological signs of akinesia, muscular rigidity, and tremor. However, these were very early and prominent features of group C. The single patient in group $\mathrm{D}$ had not had any observable evidence of amyotrophy, but neurophysiological investigations of muscular denervation had not been performed.

\section{SPET findings}

Of the seven patients scanned (table 2), the three from group B had symmetrical reduction of tracer uptake in the frontotemporal lobes. One patient from group A with very rapid decline and modest frontotemporal atrophy had a normal scan. One patient from group $C$ had reported "anterior change in a subcortical distribution" in keeping with the pathological findings. Another patient from group C, with severe ritualistic behaviour, had a normal scan. The single patient from group $\mathrm{D}$ had asymmetrical frontal lobe changes on scanning.

\section{Discussion}

To date there have been only two other major studies $^{24}$ and a couple of case reports ${ }^{1516}$ on the histopathology of these non-Alzheimer forms of dementia. 
Brun $^{4}$ described the pathological changes in the brains of 20 patients suffering from DFT. Four showed a frontal or frontotemporal atrophy characterised histologically by neuronal loss, a moderate or severe gliosis and a fine superficial spongiosus. All cases had swollen (Pick type) cells and inclusions (Pick bodies); a diagnosis of Pick's disease was ascribed. The hippocampus and amygdala were slightly or moderately affected in these patients. The other 16 patients showed mostly a frontal and anterior temporal degeneration characterised by neuronal loss, slight gliosis, but prominent "spongiosus" of layers I-III. Although occasional "swollen cells" were found in four patients, none demonstrated inclusions. The hippocampus and amygdala were slightly affected in a minority (three) of patients; in these a diagnosis of frontal lobe degeneration was given. Knopman et $a l^{2}$ reported the pathological changes in 14 patients with a condition they termed "dementia lacking distinctive histological features" (DLDH). These showed a mild to moderate atrophy of the frontal lobes in which the histological changes comprised of a vacuolation of the second cortical layer and an astrocytosis that was prominent in the deeper layers in some patients but generalised in others; no senile plaques or neurofibrillary tangles were seen and no swollen neurons or ones containing inclusions were present. The hippocampus was affected in all patients where areas CAl and subiculum showed cell loss and gliosis. The amygdala was inconsistently affected and several patients showed striatal and thalamic gliosis. Although the nucleus basalis and locus caeruleus were mostly unaffected, the substantia nigra was always, though variably, damaged. Five patients also showed hypoglossal degeneration and of these, at least two had developed clinical motor neuron disease. These latter patients appear to conform to other reports $^{6717}$ of MND with dementia in which the cortical degeneration, typified by large cell loss, gliosis, and spongiform change, is augmented by severe nigral degeneration and involvement of cranial nuclei and anterior horns. Although in MND and dementia no swollen cells or inclusions are readily observable in cortical regions in routine histological preparations immunohistochemistry ${ }^{17}$ has highlighted the presence of inclusions within the dentate gyrus of the hippocampus and lamina 2 of the frontal cortex that seem specific for this condition. Such inclusions are ubiquitin-positive but tau and silver negative ${ }^{17}$; findings that set them apart from the inclusions of Pick's disease, within these same cell types, that are both tau and ubiquitin positive, as well as argyrophilic (see here, patients 6,7 , and reference 17 ). Such cortical and hippocampal inclusions are not seen in typical $\mathrm{MND}^{17}$ without dementia. Knopman et $a l^{2}$ did not use immunostaining in their study, so it is not clear whether all five of their demented patients showing cortical, striatal, and hypoglossal changes could be classed in this way.
The four patients which we have classed as type A would appear to conform both clinically and pathologically (as do those of Kim et $a l^{15}$ and Masse et $a l^{16}$ ) to those 16 patients designated by Brun, ${ }^{4}$ as having frontal lobe degeneration and those nine patients (without hypoglossal involvement) which Knopman et $a l^{2}$ have termed as having DLDH. Of the four patients designated by us as type B, at least two (patients 6 and 7) clearly conform, on the basis of the topographical distribution of the brain atrophy, the large cortical cell loss and pronounced gliosis and the presence of tau and ubiquitin positive inclusions within the hippocampus and neocortex, to a diagnosis of typical Pick's disease. The other two patients in this group appeared histologically identical except that the inclusions were not present; whether these should also be classed as Pick's disease remains uncertain, though in the absence of any definitive marker distinguishing such cases with or without Pick bodies it seems safest at present to include all under the rubric of Pick's disease.

Another major concern is to what extent are patients represented by type A or type B (with or without Pick cells) pathologies members of one and the same disease entity? Certainly in the past patients dying with loss of large cortical nerve cells, gliosis, and spongiform change, in the absence of Alzheimer-type lesions or typical Pick cells or inclusions, have been considered to represent variants of the Pick's disease spectrum. ${ }^{18} 19$ While DFT and Pick's disease are clinically very similar and display overlapping neuropsychological profiles ${ }^{6}$ it is apparent from this present study that distinctions other than the presence or absence of swollen cells and cellular inclusions $\left(\mathrm{see}^{24}\right)$ set them apart. For example, in DFT a spongiform degeneration of the superficial cortex is a prominent feature and astrocytosis is only mild. A family history of a similar disorder seems to be strongly associated with this pathology (see here and Knopman et $a l^{2}$ ). In our four patients with "Pick's disease", spongiform change was not prominent though astrocytosis was florid; in most instances (3/4) a family history did not seem to be a feature of this pathology. Hence, there may be good grounds for drawing a clear distinction between DFT and Pick's disease on both pathological and demographic grounds.

Our single patient in group D shows close pathological similarity to those with DFT and motor neuron disease, both in general histological $^{8}$ and in immunocytochemical ${ }^{17}$ features. On clinical examination no signs of amyotrophy were present but neurophysiological evidence of denervation was not sought. The spinal cord was not available for inspection in this patient, though examination of the brainstem showed no obvious cell loss from the hypoglossal nucleus and a normally myelinated corticospinal tract. Nonetheless, the frontal lobe spongiform degeneration ${ }^{8}$, the hippocampal and nigral changes, ${ }^{8}$ and the ubiquitin positive inclusions ${ }^{17}$ are all indicative of the disease and are quite distinct from 
patients with DFT (type A) alone. It is possible that this patient had a more chronic form of DFT and MND (duration of illness was at least four years compared with the 2-3 years typically seen ${ }^{8}$ ) and that given time clinical signs of MND might well have emerged.

The remaining patients (patients 9-11) collected into group $\mathrm{C}$ are enigmatic. Their extreme striatal degeneration sets them apart from the other three subgroups and suggests a primary subcortical disorder with variable cortical involvement. Although a family history occurred in patient 11 , this was not apparent in the other two. The extrapyramidal features and the nigral and striatal involvement in these patients are clinically reminiscent of corticobasal degeneration, ${ }^{20}$ yet the absence of the characteristic posterior parietal lobe pathology ${ }^{20}$ and the whorled basophilic inclusion $\mathrm{s}^{20}$ within nigral and other subcortical neurons would dictate an alternative diagnosis. At present the nosological status of such patients remains uncertain. Although they bear some pathological resemblance to the other groups, their stereotypic behaviour and the early emergence of extrapyramidal signs (reflecting the predominantly subcortical pathological changes) sets them apart from the more prototypical syndrome of DFT in patients from groups $\mathrm{A}, \mathrm{B}$, and $\mathrm{D}$. In these three cases the frontal and temporal cortices may be functionally deafferented rather than primarily structurally impaired.

It appears, therefore, that at present, the clinical entity of DFT is represented by at least four distinctive pathologies; frontal lobe degeneration, Pick's disease, frontal degeneration with $M N D$, and assorted striatocortical degenerations. To what extent these may reflect differing manifestations of a common or a similar aetiological event with the pathological outcome being dictated by a balance of genetic and environmental factors remains uncertain. It is also unclear how these conditions relate to another pathologically similar condition, progressive aphasia, ${ }^{92}$ in which the atrophy again principally affects frontal, temporal, and frontoparietal regions but can be symmetrical or asymmetrical (usually left $>$ right). This condition is also characterised pathologically by a loss of large cortical nerve cells, spongiform change, and gliosis in the absence of swollen cells or neuronal inclusions, even when immunohistochemical procedures are used (Mann, unpublished observations). Moreover, as well as sharing a similar pathological appearance with group A patients, there is likewise a strong familial incidence. It is possible therefore that the clinical syndrome of progressive aphasia may represent an asymmetrical distribution of a more common pathological change so that the linguistic functions of the left dominant cerebral hemisphere are impaired initially and preponderantly. Clearly a definitive answer to the nosological status of these various disorders based on morphological and clinical criteria alone is currently not available; a specific biochemical or molecular marker is necessary before a more rational basis for "lumping" or "splitting" these overlapping pathological conditions can be determined. The authors greatly acknowledge the technical assistance
given by Mr D Jones (immunochemistry), Mrs C Worsley and given by Mr D Jones (immunochemistry), Mrs C Worsley and
Mrs S Moseley (histology), and Miss M Banton (photograMrs S Moseley (histology), and Miss M Banton (photogra-
phy) towards the production of this work. We also thank Miss phy) towards the production of this work. We also thank Miss
$\mathrm{D}$ Buckley and Mrs $M$ Barringer for the preparation of the
manuscript. This study was supported in part by an MRC manuscript. This study was supported in part by an MRC Regional Health Authority (to DJ).

1 Neary D, Snowden JS, Northen B, Goulding P. Dementia of frontal type. $\mathcal{F}$ Neurol Neurosurg Psychiatry 1988;51: 353-61.

2 Knopman DS, Mastri AR, Frey WH, et al. Dementia lacking distinctive histologic features: a common noning distinctive histologic features: a common nonAlzheimer

3 Blennow K. Heterogeneity of Alzheimer's disease. $\mathrm{PhD}$ Thesis, University of Goteborg, Sweden, 1990

4 Brun A. Frontal lobe degeneration of non-Alzheimer type I Neuropathology. Arch Gerontol Geriatr 1987;6: 193-207.

5 Gustafson L. Frontal lobe degeneration of non-Alzheimer type II clinical picture and differential diagnosis. Arch Gerontol Geriatr 1987;6:209-23.

6 Neary D, Snowden JS, Mann DMA. Dementia of frontal type In: Burns A, Levy R, eds. Dementia. London: Chapman and Hall (in press)

7 Morita K, Kaiya H, Ikeda T, Namba M. Presenile dementia combined with amyotrophy: a review of 34 Japanese tia combined with amyotrophy: a review of
cases. Arch Gerontol Geriatr 1987;6:263-77.

8 Neary D, Snowden JS, Mann DMA, et al. Frontal lobe dementia and motor neurone disease. $f$ Neurol Neurosurg Psychiat 1990;53:23-32.

9 Snowden JS, Neary D, Mann DMA, et al. Progressive language disorder due to lobar atrophy. Ann Neurol 1992;30:174-83.

10 Cross RB. Demonstration of neurofibrillary tangles in paraffin section-a quick and simple method using Palmgrens technique. Med Lab Sci 1982;39:67-9.

11 Haga C, Yamaguchi H, Ikeda K, Kosaka K. PAM modified methenamine silver stain for senile plaques-comparison with $\beta$ protein immunostaining. Dementia parison with
$1989 ; 3: 417-22$.

12 Mann DMA, Brown AMT, Prinja D, et al. A morphological analysis of senile plaques in the brains of noncal analysis of senile plaques in the brains of non-
demented persons of different ages using silver, immunocytochemical and lectin histochemical staining techniques. Neuropathol Appl Neurobiol 1990;16:17-25.

13 Davies L, Wolska B, Hilbich C, et al. A4 amyloid protein deposition and the diagnosis of Alzheimer's disease; prevalence in aged brains determined by immunocytochemical compared with conventional neuropathological techniques. Neurology 1988;38:1688-93.

14 Dickson DW, Wertkin A, Kress Y, et al. Ubiquitin immunoreactive structures in normal human brains. Lab Invest 1990;63,87-99.

15 Kim RC, Collins GH, Parisi JE, et al. Familial dementia of adult onset with pathological findings of a nonof adult onset with pathological find

16 Masse C, Mikol J, Brion S. Atypical presenile dementia. ¥ Neurol Sci 1981;52:245-67.

17 Wightman G, Anderson VER, Martin J, et al. Hippocampal and neocortical ubiquitin immunoreactive inclusions in amyotrophic lateral sclerosis with dementia. Neurosci Lett 1992;139:269-74.

18 Morris JC, Cole N, Banker BQ, Wright D. Hereditary dysphasic dementia and the Pick-Alzheimer spectrum. Ann Neurol 1984;16:455-66.

19 Tissot R, Constantinidis J, Richard J. Pick's disease. In: Fredericks JAM, ed. Handbook of clinical neurology vol 2: Neurobehavioural disorders. Amsterdam: Elsevier North Holland, 1985; 233-46.

20 Gibb WRG, Luthert PJ, Marsden CD. Corticobasal degeneration. Brain 1989;112:1171-92.

21 Kirshner HS, Tanridag O, Thurman L, Whetsell wO. Progressive aphasia without dementia: two cases with focal spongiform degeneration. Ann Neurol 1987; 22:527-32. 